\title{
Thinking about Descartes' rules when writing a paper
}

\author{
Yong-Ha Kim
}

Editor-in-Chief, Archives of Plastic Surgery

Department of Plastic and Reconstructive Surgery, Yeungnam University College of Medicine, Daegu, Korea

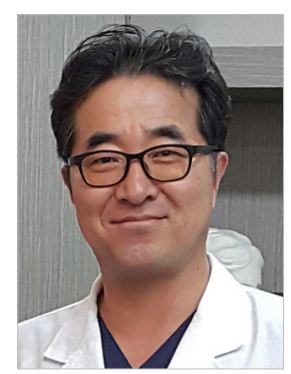

"Verba volant scripta manent (words fly, writings remain)." Latin maxim

Human beings have achieved great intellectual progress since the Printing Revolution of the 15th century. Speech and memory-dependent information has been recorded and stored in literature that is easily accessible to people, resulting in the Industrial Revolution and contributing to major advances in thought and science. As modern scientists predict, if there is a world where the human brain and the computer are connected, all information will be stored electronically and consumers will be able to access it easily.

As clinicians, we are both consumers and producers of information. Clinicians deal with patients based on abundant reserves of existing information. As their experience accumulates, clinicians can also modify existing knowledge, improve treatment methods, and articulate new and creative ideas. Simultaneously, efforts have been made to record personal experiences and novel information. However, doing so is not easy. Novice scholars worry about how to write a paper. Writing down ideas and methods quickly and clearly, without any apparent effort, seems like a special skill, and a talent to be envied.

Is there a more intuitive way to write a paper easily, such as rules or algorithms?

Descartes, the founding father of modern philosophy, made a fierce attempt to discover truth through reason alone. He presented himself as an earnest and humble seeker of truth. He resisted tradition, customs, and authority and stuck to Plato's logos, with the goal of modernizing the goals of ancient Western philosophy. Therefore, the ultimate truth for Descartes was
"Cogito, ergo sum (I think, therefore I am)." He gave mankind the brilliant logical insight that humans have the basis of truth in their own reason. In his famous book Discourse on the Method, he described how to conduct rational inquiry and how to seek truth in science $[1,2]$. In that book, he described in detail the process of finding the truth. As scientists, we need to look at the process he described for discovering truth. The "rules" for finding the truth are presented in Part 2, as follows.

The first was never to accept anything as true if I did not know clearly that it was so. The second was to subdivide each of the problems that I was about to examine into as many parts as would be possible and necessary to resolve them better. The third was to guide my thoughts in an orderly way by beginning with the objects that are the simplest and easiest to know and to rise gradually, as if by steps, to knowledge of the most complex, and even by assuming an order among objects in cases where there is no natural order among them. And the final rule was; in all cases, to make such comprehensive enumerations and such general reviews that I was certain not to omit anything [1].

Descartes described a revolutionary new method of thinking in his book. The content is too clear and grounded to ignore these rules as outdated guidelines proposed 400 years ago. These rules still provide effective help in scientifically analyzing and understanding objects, and then expressing that understanding. If we apply the above rules when analyzing any piece of knowledge or technique, it will help us to conduct our analysis in a more reliable and technically transparent way. Try to find 
a problem you do not understand! You can then solve the problem by subdividing it into small parts. Focus on the simplest and easiest thing to solve first. Then, after completely solving the problem, arrange it in order, and list the steps in their entirety without omission. These problem-solving methods can be applied not only to geometric objects, but also to more general objects and processes, such as skill acquisition, analyzing information in contexts ranging from sports to surgical techniques, and writing articles. Being able to apply Descartes' method to our papers is truly an exciting possibility!

Writers should also carefully consult modern guidelines. Information about such guidelines is easily accessible through the Instructions for Authors section of the Archives of Plastic Surgery (APS) homepage. In particular, please consult the sub-section entitled "Reporting Guidelines for Specific Study Designs," which contains information on the CONSORT, STARD, PRISMA, STROBE, and MOOSE guidelines [3]. These guidelines contain many valuable rules that are highly recommended. There is a tremendous amount of information available to help you write your paper.

Faith in the power of reason has been a great asset to mankind. If we apply the rules developed by Descartes to analyze any area of knowledge or skill, it will certainly help us to deliberate more clearly and explicitly. Rationally recording and accumulating valuable personal experiences and thinking will provide new information and inspiration to the many scholars who will follow in our footsteps. APS is always eager to serve as a venue for publishing and disseminating novel findings $[4,5]$.

\section{NOTES}

\section{Conflict of interest}

No potential conflict of interest relevant to this article was reported.

\section{ORCID}

Yong-Ha Kim https://orcid.org/0000-0002-1804-9086

\section{REFERENCES}

1. Descartes R, Clarke MC. Discourse on method and related writings. London, Penguin books; 2003.

2. Discourse on the method [Internet]. Wikipedia [cited 2018 Sep 12]. Available from https://en.wikipedia.org/wiki/ Discourse_on_the_Method.

3. Kim YH. How to review a paper for Archives of Plastic Surgery, communicate as a reviewer, and handle disagreements with authors. Arch Plast Surg 2018;45:1-3.

4. Hong JP. Putting together a global effort. Arch Plast Surg 2017;44:259-60.

5. Lew DH. PRS Korea 2016: 50th Anniversary of the Korean Society of Plastic and Reconstructive Surgeons and Another Successful Congress for Plastic and Reconstructive Surgery. Arch Plast Surg 2017;44:1-2.

Correspondence: Yong-Ha Kim

Department of Plastic and Reconstructive Surgery, Yeungnam University College of Medicine

170 Hyeonchung-ro, Nam-gu, Daegu 42415, Korea

Tel: +82-53-620-3481, Fax: +82-53-626-0705, E-mail: kimyon@ynu.ac.kr

Received: 4 Sep 2018 •Revised: 6 Sep 2018 • Accepted: 8 Sep 2018

pISSN: 2234-6163 • elSSN: 2234-6171

https://doi.org/10.5999/aps.2018.01025・Arch Plast Surg 2018;45:393-394 